\title{
Modelagem numérica de lavra de mina: estudo de caso
}

O uso dos recursos minerais está cada vez maior, e com isto, vem aumentando a necessidade de otimização dos processos de extração, isso para que se possa extrair o máximo possível de uma mina sem que se tenha desperdício de material, máquinas e até mesmo de minério, por exemplo, presente em pilares superdimensionados. Neste contexto, durante a concepção de como se irá efetuar uma lavra de uma mina, sendo o local ou o tipo de mineral de interesse, devese levar em consideração o método de extração, a forma da cava e as características mecânicas do maciço rochoso, isto ditará o formato de exploração e a configuração final da mina. Portanto, é imprescindível optar pelo método de análise que contemple uma vasta gama dos parâmetros do solo/rocha existentes na mina. O objetivo deste trabalho é a análise da estabilidade durante o processo de escavação da mina, através da análise de uma escavação da mina por modelagem numérica pelo método de elementos finitos. Para tal, adotou-se um modelo do maciço rochoso e estimou-se os parâmetros geomecânicos do maciço com base em dados da literatura. Porém, para ampliar os resultados foi adicionado outro modelo onde se ignora as fraturas do quartzito, para a avaliação da influência das mesmas no maciço.

Palavras-chave: Estabilidade de escavação; Método por Elementos Finitos; Escavação subterrânea.

\section{Numerical Modeling of Mine Mining: case study}

The use of mineral resources is increasing, and with this, the need for optimization of the extraction processes is increasing, so that as much as possible can be extracted from a mine without having waste of material, machines and even of ore, for example, present in oversized pillars. In this context, when designing how a mine will be mined, regardless of the location or type of mineral of interest, consideration should be given to the extraction method, pit shape and mechanical characteristics of the rock mass, this will dictate the exploration format and final configuration of the mine. Therefore, it is essential to opt for the method of analysis that covers a wide range of soil / rock parameters in the mine. The objective of this work is the stability analysis during the mine excavation process, through the analysis of a mine excavation by numerical modeling by the finite element method. To this end, a rock mass model was adopted and the geomechanical parameters of the rock mass were estimated based on literature data. However, to broaden the results, another model was ignored where quartzite fractures are ignored to evaluate their influence on the massif.

Keywords: Excavation stability; Finite Element Method; Underground excavation.

Topic: Engenharia Geotécnica

Reviewed anonymously in the process of blind peer.
Received: 14/01/2019

Approved: 15/03/2019
Luiz Carlos Nolêto de Oliveira Neto

Instituto Tocantinense Presidente Antônio Carlos Porto, Brasil http://lattes.cnpq.br/73333559820380327

luizneto.noleto@gmail.com

Talita Caroline Miranda

Universidade Federal do Tocantins, Brasil

http://lattes.cnpq.br/7173437103345457

talitamiranda@itpacporto.com.br

\section{Referencing this:}

OLIVEIRA NETO, L. C. N.; MIRANDA, T. C.. Modelagem numérica de lavra de mina: estudo de caso. Engineering Sciences, v.7, n.1, p.49-60, 2019. DOI: http://doi.org/10.6008/CBPC2318-3055.2019.001.0006 


\section{INTRODUÇÃO}

O uso do solo/rocha está presente na vida dos homens desde antes de deixarem de ser considerados nômades, pois sempre necessitaram dos minerais para construir armas, acessórios, joias e outros materiais. Mas desde a Revolução Industrial que o uso dos materiais presentes no subsolo deu uma grande guinada, pois surgiram novas demandas sem precedentes. Essa nova ordem mundial desencadeou avanços tecnológicos, muitas vezes não por simples entusiasmo, mas por necessidades, visando atender os anseios do mercado. Essa grande procura se dá pela enorme dependência das indústrias pelos mais diversos minerais, o Brasil em 2015 teve como resultado da produção mineral uma arrecadação de US\$26bi, tendo um saldo de mais de US\$19bi (IBRAM, 2016).

Aliando o aumento da extração aos avanços da ciência e de tecnologias, surgiram novas ferramentas para auxiliar na obtenção de resultados mais precisos e que refletem na economia e segurança; um exemplo são as modelagens numéricas bi e tridimensionais. Mas apenas nos últimos anos que estes tipos de modelagens ganharam força, pois significativos avanços tecnológicos na área computacional possibilitou que computadores de pequeno porte obtivessem grande capacidade de processamento (BARBOSA, 2011). Portanto, foi escolhida uma mina na região para que fosse realizado uma análise de uma possível escavação subterrânea. Essa análise contemplou o método indicado para a fase de projeto de uma mina (BARBOSA, 2011), que é o emprego do Método dos Elementos Finitos (MEF) em um modelo bidimensional. Isso possibilita a avaliação da movimentação do maciço durante a escavação e outros testes.

\section{REVISÃO TEÓRICA}

\section{Escavação subterrânea}

Este item apresenta sucintamente uma revisão sobre escavação subterrânea, comportamento mecânico de maciços e modelagem numérica. A princípio, a lavra a céu aberto ganha a dianteira no mercado pelas suas vantagens, que são, de certa forma, bem vastas. Exemplos dessas vantagens são o custo de lavra, a capacidade de produção e ambientes menos agressivos. Porém, entre suas desvantagens há uma crucial, que é em relação a profundidade em que se encontra o corpo do minério que se espera explorar, e é aí que entra a lavra subterrânea (CARLI, 2013).

Uma intervenção comum ao maciço de um solo e/ou rocha são os túneis, que têm como principal objetivo transpor obstáculos impostos pela natureza ou pela ação do homem, ou seja, são essencialmente componentes de transporte, diferenciando apenas no que se refere a mineração (MARANGON, 2006). Essa diferenciação de objetivos se dá pelo fato de que os túneis, em minas subterrâneas, têm como intuito dar acesso ao corpo do minério de interesse.

Portanto, geralmente quando se pensa em túneis, remete-se aos túneis civis, em que se tem, durante seu desenvolvimento, uma face simples, e que em grande parte conta com grandes investimentos em contenções. Já os túneis de mineração contam com várias aberturas, que têm sua permanência relativamente curta e suas contenções são pontuais e o responsável controla as deformações (SILVA, 2018). 


\section{Comportamento mecânico}

O comportamento mecânico induzido aos maciços rochosos escavados se dá através da interligação de diversos fatores, como por exemplo: as descontinuidades, as orientações espaciais e suas características geomecânicas (FIGUEIREDO, 2016). Marangon (2006), na sua linha de estudo, que são os túneis civis, diz que o alinhamento básico de um túnel é orientado pelo interesse primário do tráfego e do transporte, mas adequando para o estudo em questão, será orientado pelos interesses de extração. Conforme Marangon (2006), a localização exata é controlada pelos fatores geológicos e hidrológicos que o meio impõe.

Os fatores geológicos são os mais diversos e vária de acordo com o local, mesmo que a composição do local seja de materiais já conhecidos, ainda há a necessidade de estudos. Alguns desses estudos levam a fatores necessários para se entender melhor o possível comportamento do maciço em estudo, sendo eles: classificação do maciço, alterabilidade da rocha e efeitos tectônicos (CAPUTO, 2012). Esses efeitos tectônicos atuam diretamente sobre a perfuração, pois como o túnel se encontra nos tipos de rochas e suas estratigrafias, pode variar de acordo com casos específicos, conforme exemplo nas figuras 1 e 2.

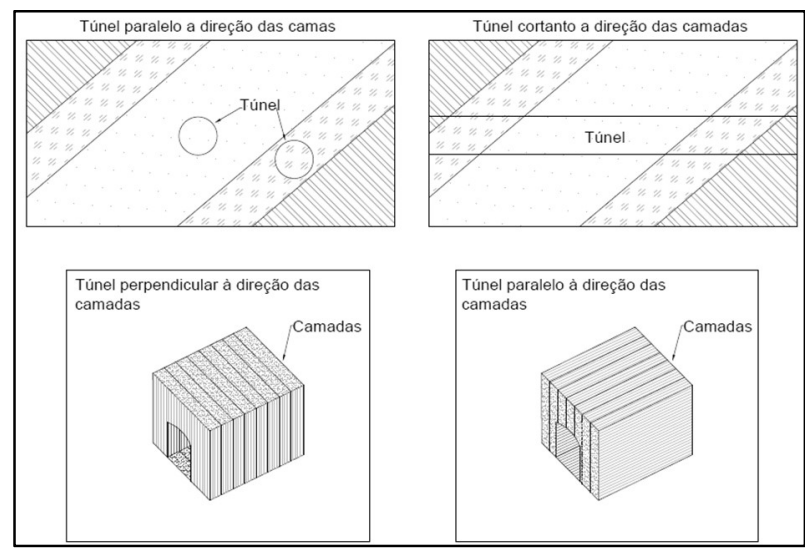

Figura 1: Túneis em relação a direção das camadas. Fonte: Marangon (2006).

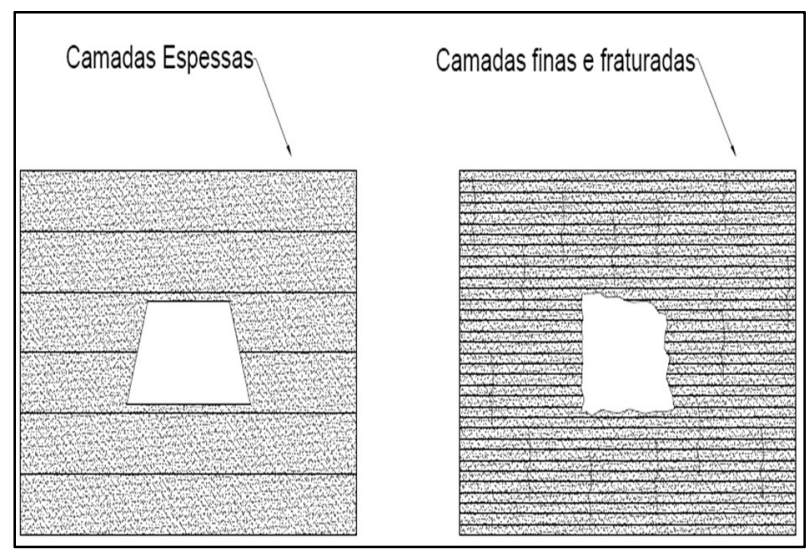

Figura 2: Espessuras das camadas. Fonte: Marangon (2006) modificado.

Geralmente, quando se fala de placas tectônicas e seus efeitos, o brasileiro se sente imune a seus efeitos diretos de movimentos. Essa é uma cultura errônea quando se fala em geologia, pois existe uma ligação real nos efeitos que as placas tectônicas impõem sobre o maciço rochoso. Esses movimentos podem ser tanto verticais como horizontais, com esforços de tração e compressão, fazendo com que na forma da superfície terrestre surja dobras e falhas. As dobras ou a curvatura são divididos em Anticlinal e Sinclinal, como mostra a figura 3 a seguir (CAPUTO, 2012).

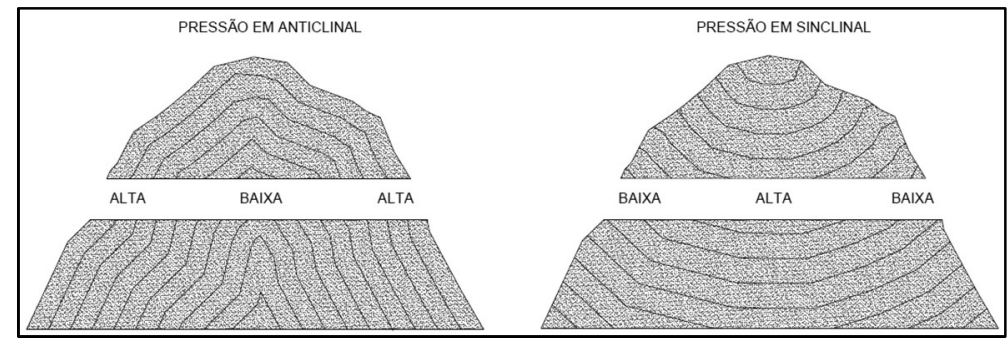

Figura 3: Pressão de acordo com a curvatura dos extratos. Fonte: Marangon (2006). 
Enfim, o que a forma influencia no comportamento mecânico? Para Caputo (2012), quando se faz um corte qualquer no maciço rochoso, deve-se saber que, em zonas anticlinais, a água escorre para seu interior e as pressões são maiores nos extremos do túnel, por exemplo, e quando é uma sinclinal, os efeitos são opostos. E afinal, como se chegar ao comportamento aproximado de um material que em regiões e orientações diferentes têm suas propriedades modificadas?.

Azevedo et al. (2006) indicou que um ponto de partida para a predição do comportamento aproximado de um material em regiões e orientações diferentes, com propriedades modificadas, é conhecer algumas propriedades da rocha sã, das descontinuidades e do maciço rochoso com um todo. Estas propriedades podem ser obtidas através da medição direta das propriedades fundamentais ou estimar as proprieades em comparação com a literatura.

\section{Modelagem Numérica}

A modelagem numérica é realizada através de três princípios básicos, que são o préprocessamento, processamento e pós-processamento. Sendo o primeiro para a preparação das condições inicias e de contorno; o segundo é quando se realiza a execução do modelo; e o último é onde ocorre a preparação dos campos de saída para a visualização (CAVALCANTE, 2016). A modelagem numérica é produzida para realizar simulações construtivas e ainda possibilita modelos construtivos que reproduzam os comportamentos dos mais diversos constituintes presentes no maciço do solo (LIMA, 2002). Ela consiste em uma análise matemática que realiza uma segmentação de um meio contínuo em pequenos elementos, sem modificar suas propriedades inicias e avaliando cada parte (LOTTI et al., 2006).

As aplicações para a modelagem numérica podem ser qualitativas, que são a visualização do modelo usando projeções geométricas, e quantitativas, cálculos dos volumes e geração dos mapas, como, por exemplo, da declividade (FELGUEIRAS et al., 2001). Pensando na parte quantitativa, o uso do Modelo dos Elementos Finitos (MEF) permite a determinação do estado de tensão e deformação de um corpo de geometria arbitrária que pode estar sujeita a ações externas (AZEVEDO, 2003).

No que tange à mineração no Brasil, a aplicação desta ferramenta é pouco disseminada, isto se deve ao fato de majoritariamente a mineração nacional ser realizada em minas a céu aberto, onde aparentemente as exigências para este método são menores. Mas em relação a lavra subterrânea, na grande parte dos cenários geotécnicos, a não análise da concepção das lavras subterrâneas pelo método numérico, em especial ao tridimensional, se torna temerário (BARBOSA, 2011).

\section{METODOLOGIA}

\section{Área de estudo}

Este item descreve a área de estudo e o fluxo metodológico aplicado nesta pesquisa. $\mathrm{O}$ estudo de caso foi realizado sobre uma mina a céu aberto, conforme se pode visualizar ilustrado na figura 4, localizada no estado do Tocantins, mais precisamente no município de Monte do Carmo (TO). Sobre a geologia local, a 
região de estudo se localiza em duas faixas de estudos de rochas, sendo elas: Faixa Araguaia e Faixa Brasília, com rochas metassedimentares, ou seja, que têm como protólito alguma rocha sedimentar, e com ou derivados de rochas ígneas, respectivamente (ALMEIDA et al., 1981).

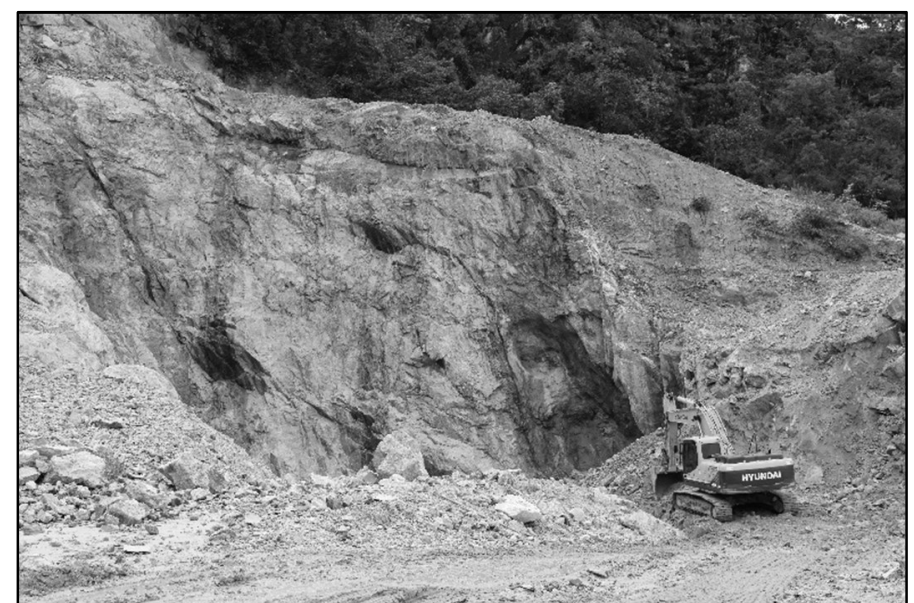

Figura 4: Lavra a céu aberto, local da mina. Fonte: Dias et al. (2017).

A geologia deste local é ácida, com seus extremos demarcados a oeste por falhas ou com coberturas coluvionares, sendo sua orientação NNE-SSW, com o Complexo Porto Nacional. O Granito do Carmo localizado ao sul choca-se em contatos bruscos, provavelmente de origem intrusiva, isto pelo fato de se encontrar enclaves riolíticos isolados na massa gramlica, próximo a seus bordos, e a leste é coberto discordantemente por sedimentos da Bacia do Pamaíba. Associam-se também a essas zonas ocorrências minerais filonianas, trata-se, essencialmente, de veios de quartzo centimétricos a métricos, mincralizados a ouro e sulfetos, sobretudo galena e pinta (DIAS et al., 2017).

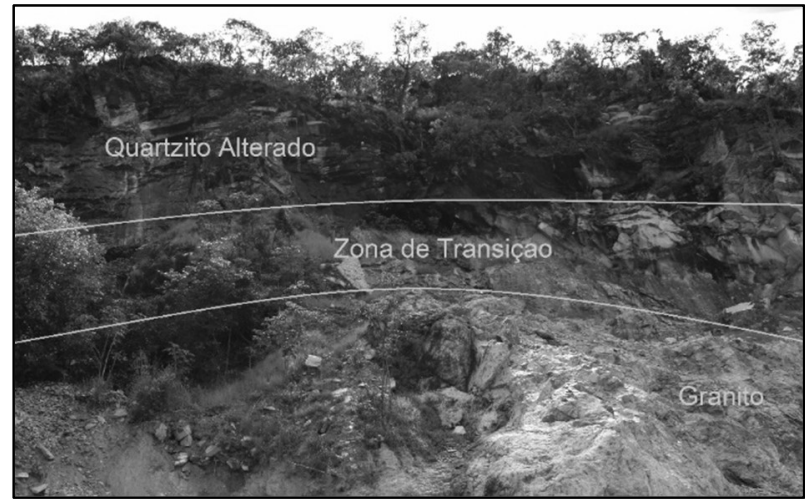

Figura 5: Estratigrafia local. Fonte: Dias et al. (2017).

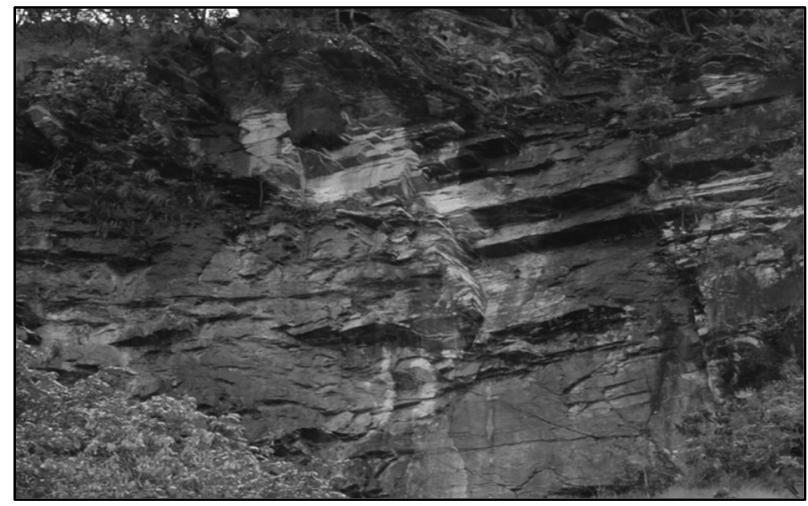

Figura 6: Quartzito com falhas na horizontal. Fonte: Dias et al. (2017).

A mina em questão abriga as singularidades citadas, com os dois tipos de rochas, o quartzito e o granito. No local escolhido para a extração o quartzito sem encotra alterado sob o granito, já o granito está em estado levemente alterado. Segundo os estudos realizados no local (DIAS et al., 2017), os minérios de interesse se concentram no contato entre essas duas rochas, isto é, se encontra em maior quantidade na zona de transição, de acordo com a figura 5. A figura 6 apresenta o detalhe do quartizito e seus planos de falhas horizontais; já a figura 7 apresenta o grau de alterabilidade do granito. 0 sistema de lavra atual é por 
céu aberto, mas devido a estudos que revelaram que os minérios se concentram na zona de transição, surgiu a ideia de um estudo acerca da implementação de lavra subterrânea no local.

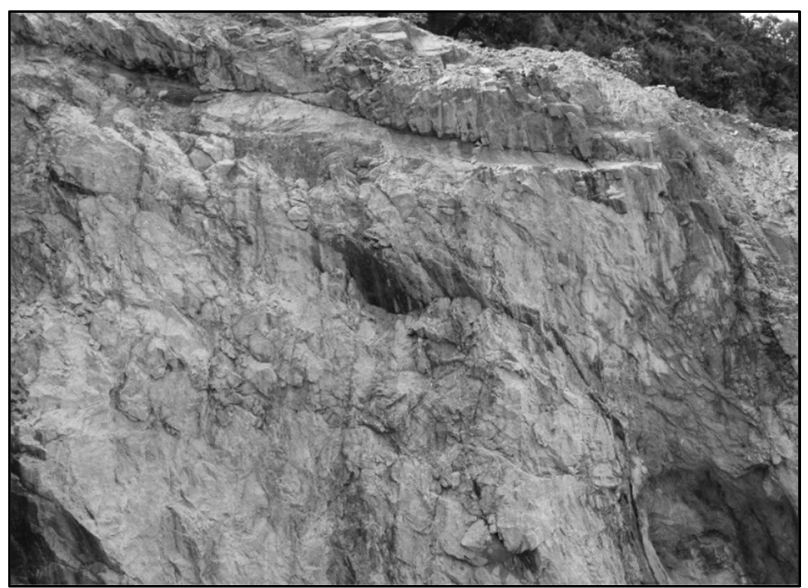

Figura 7: Granito levemente alterado. Fonte: Dias et al. (2017).

Uma das premissas fundamentais para a realização da modelagem numérica é o uso dos dados de propriedades dos materiais com base em ensaios in situ ou em laboratório. Como não foi possível a realização dos mesmos, pois no estado do Tocantins não há laboratório de Mecânica das Rochas optou-se por estimar as propriedades mecânicas do maciço com base nos dados de literatura. As propriedades das rochas que foram escolhidas para a criação dos modelos numéricos, foram: Coesão (c); Ângulo de Atrito (Ф); Modulo de Elasticidade (E); Coeficiente de Poisson (U); e Peso Específico ( $($ ). Com isso as propriedades encontradas para ambas as rochas, de acordo a literatura, foram propostas na tabela 1.

Tabela 1: Propriedades das rochas.

\begin{tabular}{|c|c|c|c|}
\hline ROCHA & PROPRIEDADE & VALORES & LITERATURA \\
\hline \multirow{4}{*}{\begin{tabular}{c} 
Quartzito (alterado) \\
\cline { 2 - 3 }
\end{tabular}} & Coesão $(\mathrm{kPa})$ & $250-700^{1}$ & (AGUILERA, 2009) \\
\cline { 2 - 4 } & Ângulo de Atrito $\left(^{\circ}\right)$ & $40-55^{1}$ & (AGUILERA, 2009) \\
\cline { 2 - 4 } & Modulo de Elasticidade $(\mathrm{mPa})$ & $74.100^{2}$ & (CAPUTO, 2012) \\
\cline { 2 - 4 } & Coeficiente de Poisson & 0,26 & (ALECRIM, 2012) \\
\hline \multirow{4}{*}{$\begin{array}{c}\text { Granito (levemen) } \\
\text { alterado) }\end{array}$} & Peso Específico $\left(\mathrm{kN} / \mathrm{m}^{3}\right)$ & 27,4 & $($ AGUILERA, 2009) \\
\cline { 2 - 4 } & Coesão $(\mathrm{kPa})$ & $45-500^{1}$ & (AGUILERA, 2009) \\
\cline { 2 - 4 } & Ângulo de Atrito $\left(^{\circ}\right)$ & $20.005^{2}$ & (CAPUTO, 2012) \\
\cline { 2 - 4 } & Modulo de Elasticidade $(\mathrm{mPa})$ & 0,1 & (CAPUTO, 2012) \\
\cline { 2 - 4 } & Coeficiente de Poisson & 28 & (PINHEIRO, 2007) \\
\hline
\end{tabular}

Legenda: ${ }^{1}$ Foi tirada uma média simples; e ${ }^{2} 1 \mathrm{~kg} / \mathrm{cm}^{2}$ equivale a $98,07 \mathrm{mPa}$, com isso o valor será aproximado.

\section{Modelos numéricos}

Para a realização desta pesquisa optou-se por simular a escavação subterrânea de um túnel circular com 2 metros de diâmetro, com o objetivo de avaliar as diferenças entre os módulos/métodos de análise de estabilidade da escavação por elementos finitos. Foram criadas duas hipóteses para a modelagem, a primeira considerando o quartzito como um maciço sem as falhas horizontais, chamado de 'Sem Fissuras'. Já a segunda hipótese considerou-se o quartzito fraturado horizontalmente, nomeado 'Com Fissuras'.

O granito abaixo do quartzito, foi considerado levemente alterado e sem falhas para ambas hipóteses. Esta definição de dois modelos permite a verificação da influência das fraturas na estabilidade do maciço. Para este estudo foi escolhido o programa numérico Optum G2, que faz análises de estabilidade e 
de deformabilidade geotécnica. O programa permite realizar analises possibilitam encontrar as tensões iniciais do maciço, a carga limite máxima de aplicação, o fator de segurança e muitos outros.

\section{Etapas de confecção dos modelos}

No programa existem quatro módulos para a criação completa do modelo: Geometria, Materiais, Entidade e Resultados (esta janela será discorrida apenas no capitulo Resultados), que foram seguidos à risca e destrinchados. No módulo Geometria, elabora-se a forma do maciço que será o objeto de estudo, e onde também se confecciona os cortes em cada etapa de análise. No modelo elaborado foi estabelecida uma área de $50 \times 50 m$ (figura 8 a), com cada camada de rocha com uma espessura de $25 \mathrm{~m}$ cada.

Já no módulo Materiais é onde se atribui a cada camada o material e suas propriedades. O programa já vem com alguns materiais pré-definidos, no caso foi criado o material Quartzito (laranja) e também Granito (verde), com todas as propriedades já citadas (figura 8b). Por fim, no módulo chamado Entidades, permite que se adicione as cargas, as restrições do maciço, nível de água e outros. Como no modelo em estudo é realizado apenas cortes no maciço, nesta etapa é incluída apenas a restrição completa nas bordas laterais e inferior (figura 8c).

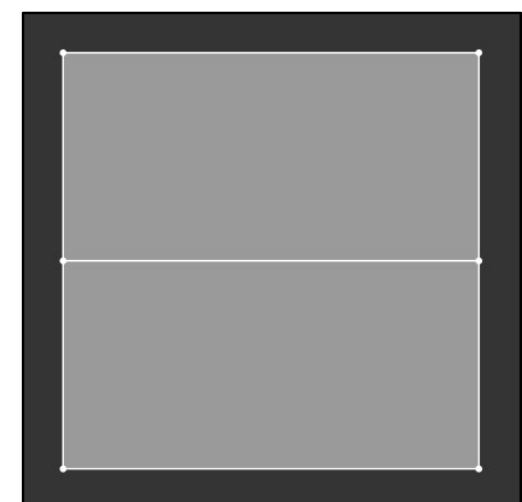

a) Definição dos limites

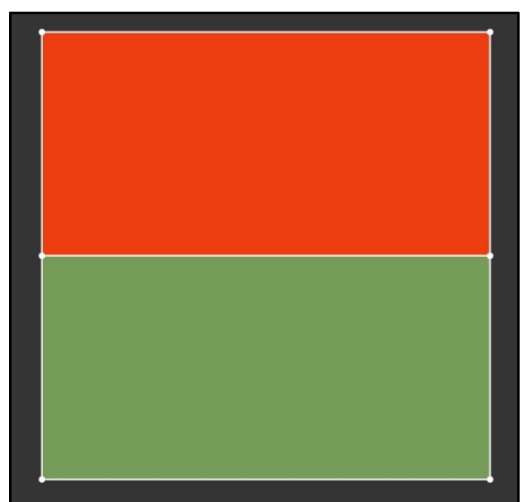

b) Atribuição os materiais

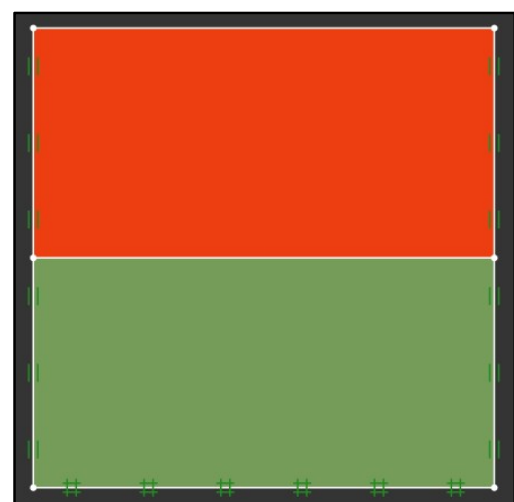

c) Atribuídos as restrições de movimentos

Figura 8: Etapas de confecção do modelo numérico.

\section{Etapas de análise}

Neste ponto, foram criados os estágios e atribuídos à cada um deles uma análise específica. Ao todo, foram criados 13 estágios, para cada qual suas formas podem ter sido alteradas para que se possa chegar à forma desejada da escavação no maciço rochoso. Foi estabelecido que a escavação analisada é do tipo circular, com seu centro no encontro das camadas de quartzito e granito e com um diâmetro de $2 \mathrm{~m}$. Com o intuito de simular a escavação por partes, dividiu-se o modelo em 4 partes ou quadrantes, onde o subsequente será executado depois da finalização e estabilização do anterior (figura 9). A criação dos estágios se deu de acordo a tabela 2. As hipóteses e modelos adotados são apresentados na tabela 3. 


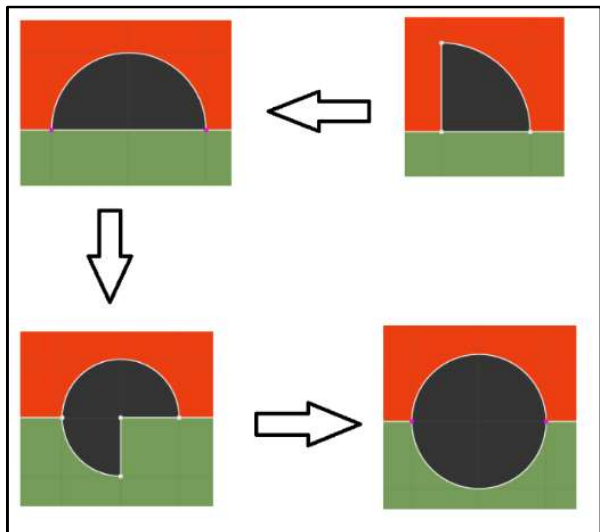

Figura 9: Etapas de escavação.

Tabela 2: Estágios de análise numérica.

\begin{tabular}{|c|c|c|}
\hline Estágio & Vínculo & Análise \\
\hline Tensão Inicial & - & Tensão Inicial \\
\hline Escavação 1 & Tensão Inicial & Elastoplástico $^{1}$ \\
\hline RR 1 Inf & Escavação 1 & Redução de Resistência $^{2}$ \\
\hline RR 1 Sup & Escavação 1 & Redução de Resistência \\
\hline Escavação 1-2 & Escavação 1 & Elastoplástico \\
\hline RR 1-2 Inf & Escavação 1-2 & Redução de Resistência \\
\hline RR 1-2 Sup & Escavação 1-2 & Redução de Resistência \\
\hline Escavação 1-2-3 & Escavação 1-2 & Elastoplástico \\
\hline RR 1-2-3 Inf & Escavação 1-2-3 & Redução de Resistência \\
\hline RR 1-2-3 Sup & Escavação 1-2-3 & Redução de Resistência \\
\hline Escavação 1-2-3-4 & Escavação 1-2-3 & Elastoplástico \\
\hline RR 1-2-3-4 Inf & Escavação 1-2-3-4 & Redução de Resistência \\
\hline RR 1-2-3-4 Sup & Escavação 1-2-3-4 & Redução de Resistência \\
\hline
\end{tabular}

Legenda: ${ }^{1} \mathrm{e}^{2}$ análises para se encontrar o deslocamento máximo e o fator de segurança, respectivamente.

Tabela 3: Descrição dos passos.

\begin{tabular}{|c|c|c|}
\hline Análises & Configurações & Dados \\
\hline \multirow{2}{*}{ Tensão Inicial } & Tipo de Elemento & Inferior \\
\hline & Números de Elementos & 5000 \\
\hline \multirow{7}{*}{ Elastoplástico } & Zerar Deslocamento & Não \\
\hline & Escopo de tempo & Prolongado \\
\hline & Tipo de Elemento & 6-nós-Gauss \\
\hline & Números de Elementos & 5000 \\
\hline & Número de Incrementos & 1 \\
\hline & Adaptação da Malha & Sim \\
\hline & Fator de Relaxamento ${ }^{1}$ & 0,3 \\
\hline \multirow{5}{*}{ Redução de Resistência } & Reduzir Resistência em & Sólidos \\
\hline & Escopo de tempo & Prolongado \\
\hline & Tipo de Elemento & Inferior e Superior $^{2}$ \\
\hline & Números de Elementos & 5000 \\
\hline & Adaptação da Malha & Sim \\
\hline
\end{tabular}

Legenda: 'Usado para que suporte possa se deformar; ${ }^{2}$ Permite uma análise menos (inferior) e mais (superior) conservadora e resultado final é uma média simples entre eles.

\section{RESULTADOS E DISCUSSÃO}

Dentre todos os resultados e análises permitidas pelo software, neste trabalho são apresentados apenas os três diagramas: esforço, deslocamento e desplacamento da malha para o último estágio de escavação 1-2-3-4 para os dois modelos: 'Sem Fissuras' e 'Com Fissuras', ressaltando que a tabela 4 apresenta os resultados mais extremos de cada estágio de escavação, mas os diagramas são, de forma pratica, a aplicação direta desses resultados no maciço. 
Tabela 4: Resultados.

\begin{tabular}{|c|c|c|c|}
\hline \multirow{2}{*}{ Estágios de Escavação } & Análises & \multicolumn{2}{|c|}{ Resultados } \\
\cline { 2 - 4 } & & Sem Fissuras & Com Fissuras \\
\hline \multirow{3}{*}{ Escavação 1 } & Deslocamento Máximo & $0,021 \mathrm{~mm}$ & $0,012 \mathrm{~mm}$ \\
\cline { 2 - 4 } & Fator de Segurança - Inferior & 8,42 & 0,41 \\
\cline { 2 - 4 } & Fator de Segurança - Superior & 8,76 & 0,77 \\
\hline \multirow{2}{*}{ Escavação 1-2 } & Deslocamento Máximo & $0,043 \mathrm{~mm}$ & $0,044 \mathrm{~mm}$ \\
\cline { 2 - 4 } & Fator de Segurança - Inferior & 7,72 & 0,12 \\
\cline { 2 - 4 } & Fator de Segurança - Superior & 7,94 & 0,59 \\
\hline \multirow{2}{*}{ Escavação 1-2-3 } & Deslocamento Máximo & $0,059 \mathrm{~mm}$ & $0,054 \mathrm{~mm}$ \\
\cline { 2 - 4 } & Fator de Segurança - Inferior & 7,24 & 0,04 \\
\cline { 2 - 4 } & Fator de Segurança - Superior & 7,42 & 0,59 \\
\hline \multirow{2}{*}{ Escavação 1-2-3-4 } & Deslocamento Máximo & $0,047 \mathrm{~mm}$ & $0,047 \mathrm{~mm}$ \\
\cline { 2 - 4 } & Fator de Segurança - Inferior & 7,15 & 0,12 \\
\cline { 2 - 4 } & Fator de Segurança - Superior & 7,31 & 0,62 \\
\hline
\end{tabular}

\section{Resultados no modelo sem fissuras}

A tabela 4 apresenta os resultados de deslocamento máximo e o Fator de segurança Inferior e Superior para cada estágio da modelagem do modelo 'Sem Fissuras'. A figura 10 mostra os valores de variação de força normal aplicadas no entorno da escavação, a Figura 11 mostra os valores de deslocamento no entorno da escavação e a figura 12 mostra o desplacamento dos elementos da malha durante a análise numérica.

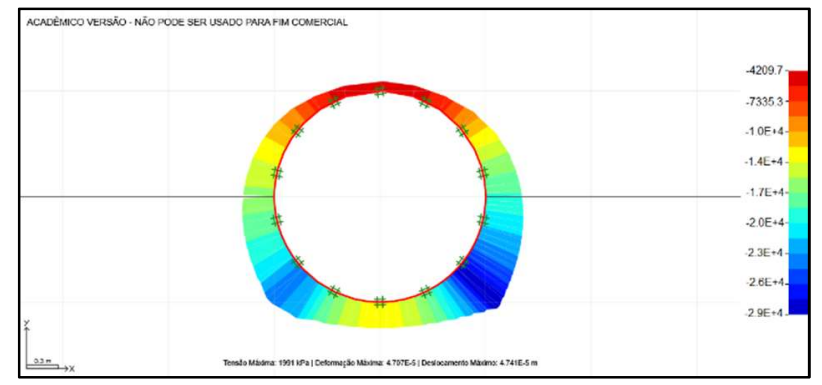

Figura 10: Força normal (kN).

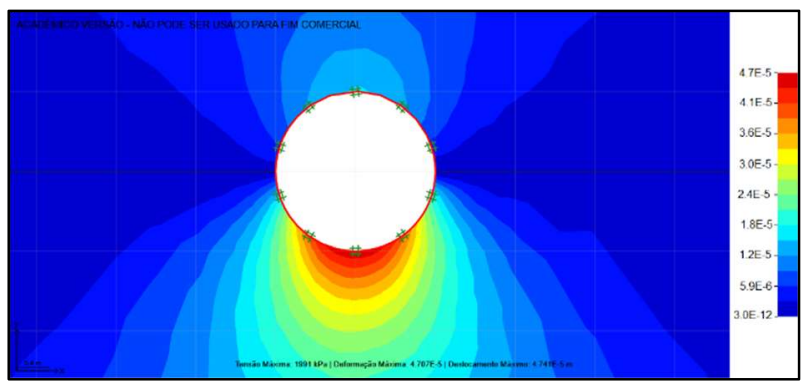

Figura 11: Deslocamento (m).

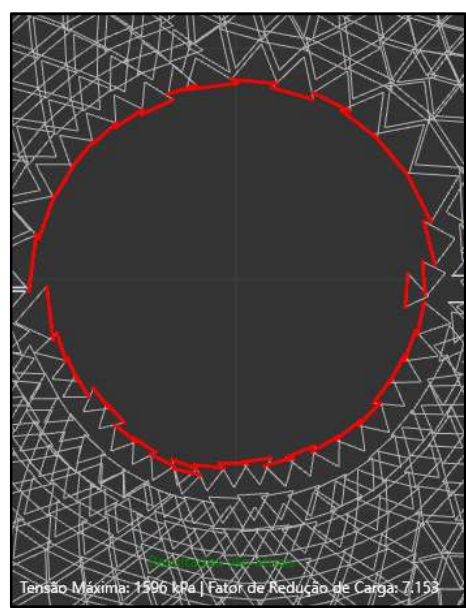

Figura 12: Desplacamento da malha.

Pode-se notar que, à medida que a escavação no maciço avança, os valores correspondentes aos deslocamentos e fatores de segurança se modificam. Os deslocamentos vão aumentando até o terceiro estágio de escavação, sendo que no último, esse valor diminui. Já os fatores de segurança têm um 
comportamento oposto, além de ter uma tendência a reduzir a medida do avanço do corte, ela continua até mesmo ao último estágio, porém o maciço é caracterizado como estável pois, os valores são maiores que 1.

\section{Resultados do modelo com fissuras}

A tabela 4 apresenta também os resultados de deslocamento máximo e o Fator de segurança Inferior e Superior para cada estágio da modelagem do modelo 'Com Fissuras'. A figura 13 mostra os valores de variação de força normal aplicadas no entorno da escavação; a figura 14 mostra os valores de deslocamento no entorno da escavação; e a figura 15 mostra o desplacamento dos elementos da malha durante a análise numérica.

O entendimento acerca dos resultados deste modelo se assemelha ao anterior, onde os deslocamentos tendem a aumentar até o terceiro estágio e diminui no último e os fatores de segurança continuam a diminuir. Mas diferentemente do modelo Sem Fissuras, este é instável, pois os fatores de segurança são inferiores a 1.

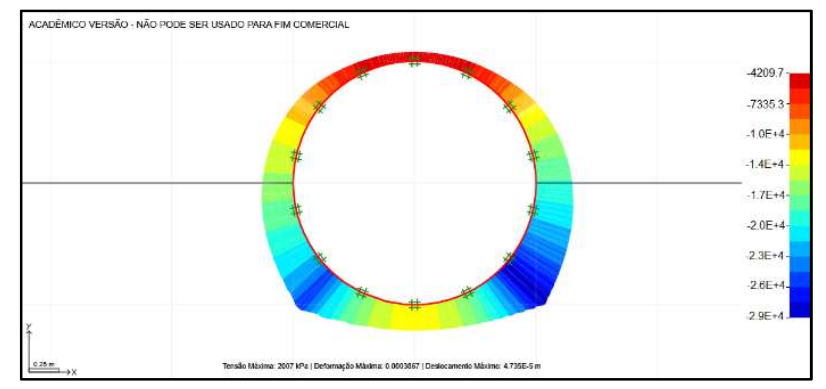

Figura 13: Força normal (kN).

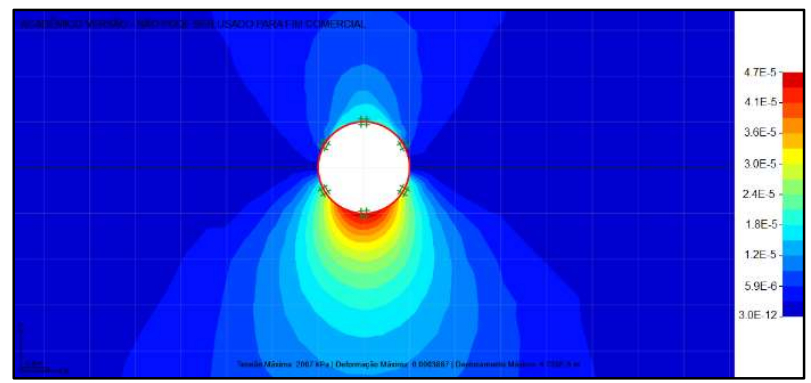

Figura 14: Deslocamento (m).

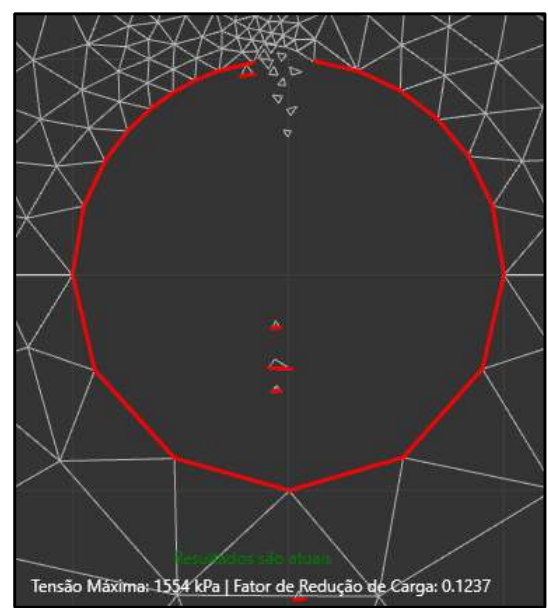

Figura 15: Desplacamento da malha.

\section{Comparação entre modelos}

Os dois modelos analisados apresentam diferentes comportamentos mecânicos. No modelo 'Sem Fissuras' onde o maciço de quartzito é considerado sem nenhum plano de falhas os valores dos fatores de segurança se encontram acima de 1, consequentemente o maciço é estável. Mas estes fatores, assim como está na tabela 4, por mais que seja estável, pode-se notar que eles não têm a tendência a se estabilizar. As deformações como nota-se não são lineares, ou seja, não aumentam de acordo com o avanço das escavações, entretanto isso acontece nos dois modelos. 
Para o modelo onde reflete a realidade do maciço, que é com as fissuras, a tabela 4 revela que o fator de segurança médio de cada estágio de escavação está abaixo de 1, fazendo com que o maciço se caracterize como instável. Isso indica a grande influência que as fissuras exercem no maciço, onde nem mesmo no primeiro estágio de escavação a instabilidade não se omite.

\section{CONCLUSÕES}

Este trabalho realizou dois modelos numéricos distintos, com o intuito de comparar os resultados om apenas a diferença do maciço ter fraturas. Através deste confronto, pode-se notar que se a rocha (quartzito) não fosse fraturada, o processo de escavação estaria seguro, ou seja, seria autoportante. 0 que fica muito claro se compararmos o fator de segurança entre os dois modelos, com uma redução de cerca de dez vezes o valor, o modelo 'Com fissuras' mais próximo da realidade, com as visitas in loco. Devido a este fato, a escavação está comprometida se não houver a implantação de contenções, portanto se houver a necessidade da implantação da lavra subterrânea no local, deve-se salientar para que durante o processo de estudos e análises deve-se adicionar contenções, que podem ser pontuais ou não.

Os resultados foram bem contundentes, isto é, de acordo como o maciço se encontra, que é com fissuras no quartzito, a escavação subterrânea sem reforço estrutural da escavação se mostra como uma alternativa inviável. Tendo em vista que o modelo numérico não contemplou contenções em sua totalidade e em pontos específicos. Isso por que a implantação de contenções aumenta os custos de implantação do túnel, e a proposta era verificar o corpo do maciço suportaria por se só os resultados do alivio de pressão, em detrimento do processo de escavação.

Outro fator preponderante: este estudo foi elaborado com propriedades que podem ser classificadas como genéricas, tem em vista que foram obtidas em literaturas que têm seus focos de estudos em diversas localidades no globo. Isso faz com que os resultados obtidos não reproduzam o comportamento real daquele maciço em questão. Portanto, a continuidade deste trabalho se dará com a obtenção dos parâmetros do maciço rochoso via ensaios in situ e de laboratório e com estes dados a recalibração do modelo com dados reais.

\section{REFERÊNCIAS}

AGUILERA, C. E.. Aplicação de Métodos de Análise de Estabilidade de Taludes de Grande Altura em Mineração. Rio de Janeiro: PUC, 2009.

ALECRIM, A. V.. Estudo do Resíduo de Quartzito Foliado para Emprego em Estruturas de Pavimentos. São Paulo: 2009.

ALMEIDA, F. F.; HASUI, Y.; NEVES, B. B.; FUCK, R. A.. Brasilian structural provinces: As introduction. Earth-Science Reviews, v.17, n.1, p.1-29, 1981.

AZEVEDO, A. F. M.. Método dos Elementos Finitos. Porto: Universidade de Engenharia do Porto, 2003.
AZEVEDO, I. C. D.; MARQUES, E. A. G.. Introdução à Mecânica das Rochas. Viçosa: EDUFV, 2006.

BARBOSA, K. J.. Avaliação geotécnica de lavra subterrânea do corpo Serrotinho da mina Cuiabá através de modelagem numérica tridimensional. Ouro Preto: UFOP, 2011.

CAPUTO, H. P.. Mecânica dos solos e suas Aplicações: Mecânica das Rochas. 6 ed. Rio de Janeiro: Livros Técnicos e Científicos, 2012.

CARLI, C. D.. Análise de Projetos Limite: Lavra a Céu Aberto vs Lavra Subterrânea. Porto Alegre: 2013.

CAVALCANTE, E. P.. Métodos de Modelagem Numérica. Campina Grande: UFCG, 2016 
DIAS, B. M.; MENDES, C. M.. Caracterização e análise de queda de bloco de seções de taude rochoso em uma cava de mineração à céu aberto de granito (estudo de caso). Porto Nacional: 2017.

FELGUEIRAS, C. A.; CÂMARA, G.. Modelagem Numérica de Terreno: Introdução a Ciência da Geoinformação. São José dos Campos: INPE, 2001

FIGUEIREDO, L. T.. Avaliação de Estabilidade de Escavações em Meios Descontínuos, a Partir de Testemunhos de Sondagem da Mina Subterrânea de Vazante/MG. Ouro Preto: UFOP, 2016

IBRAM. Instituto Brasileiro de Museus. Relatório anual IBRAM. Brasília: IBRAM, 2016.
LIMA, A. P.. Deformabilidade e estabilidade de taludes em solo grampeado. Dissertação (Mestrado) - Pontifícia Universidade Católica, Rio de Janeiro, 2002.

LOTTI, R. S.; MACHADO, A. W.; MAZZIEIRO, E. T.; JÚNIOR, J. L.. Aplicabilidade Científica do Método dos Elementos Finitos. Dental Press, Maringá, v.11, n.2, p.35-43, 2006. DOI: http://doi.org/10.1590/S1415-54192006000200006

MARANGON, M.. Tópicos em Geotecnia e Obras de Terra. Juiz de Fora: 2006.

PINHEIRO, L. M.. Fundamentos do concreto. São Carlos: Universidade de São Paulo, 2007.

SILVA, J. M.. Sustentação de Escavações Subterrâneas Civis e de Mineração. In The Mine, p.31-33, 2018.

A CBPC - Companhia Brasileira de Produção Científica (CNPJ: 11.221.422/0001-03) detém os direitos materiais desta publicação. Os direitos referem-se à publicação do trabalho em qualquer parte do mundo, incluindo os direitos às renovações, expansões e disseminações da contribuição, bem como outros direitos subsidiários. Todos os trabalhos publicados eletronicamente poderão posteriormente ser publicados em coletâneas impressas sob coordenação da Sustenere Publishing, da Companhia Brasileira de Produção Científica e seus parceiros autorizados. Os (as) autores (as) preservam os direitos autorais, mas não têm permissão para a publicação da contribuição em outro meio, impresso ou digital, em português ou em tradução. 